\title{
A CARTOGRAFIA E AS GEOTECNOLOGIAS COMO SUBSÍDIO PARA O ENSINO DE GEOGRAFIA: CAPACITAÇÃO DE PROFESSORES DE GEOGRAFIA DA REDE PÚBLICA
}

\author{
Renata Cristina Zanilatto ${ }^{(a)}$ Alexandre Magnum Leme ${ }^{(b)}$ Andréia Medinilha Pancher ${ }^{(c)}$ Ivan \\ Shieh Basotti ${ }^{(d)}$ \\ (a) Departamento de Planejamento Territorial e Geoprocessamento/Geografia, UNESP, renataczanilatto@gmail.com \\ (b) Departamento de Geologia Aplicada/ Geociências, UNESP, alexandremagnumleme@ gmail.com \\ (c) Departamento de Planejamento Territorial e Geoprocessamento/Geografia, UNESP, ivan.basotti@ gmail.com \\ (d) Departamento de Planejamento Territorial e Geoprocessamento/Geografia, UNESP, medinilh@ @r.unesp.br
}

EIXO 7: GEOGRAFIA FÍSICA - CURRÍCULO, FORMAÇÃO E PRÁTICAS DE ENSINO

\begin{abstract}
Resumo
$\mathrm{Na}$ Era da Globalização a qual nos encontramos, o ensino traz novos desafios aos educadores. A Cartografia e suas tecnologias vêm sendo empregadas de forma crescente no ensino público paulista, e esta integração da cartografia e das geotecnologias à educação escolar contribui para que os alunos sejam capazes de melhor entender as relações entre meio-ambiente e sociedade (no caso da Geografia).Para tanto, é necessário difundir, popularizar e explorar essas geotecnologias no ensino básico, conforme sugere o INPE.O presente artigo é componente de um Projeto de Extensão intitulado "Geotecnologias para alfabetização cartográfica de professores de Geografia do ensino da rede pública", realizado na Universidade Estadual Paulista e financiado pela PROEX.O projeto não se restringiu a tão somente apresentar os recursos das geotecnologias, mas também em mostrar aos educadores a contribuição dessa tecnologia para a construção do conhecimento e compreensão da realidade, possibilitando-os exercer a cidadania e o poder de intervir na realidade.
\end{abstract}

Palavras chave: CARTOGRAFIA. GEOTECNOLOGIAS. ENSINO. CAPACITAÇÃO.

\section{Introdução}

\author{
“CARTOGRAFIA - no sentido lato da palavra não é apenas uma das \\ ferramentas básicas do desenvolvimento econômico, mas é a primeira \\ ferramenta a ser usada antes que outras ferramentas possam ser postas em \\ trabalho.” (ONU, Departament of Social Affair. Modern Cartography - Base \\ Maps For Worlds Needs. Lake Success).
}

Na Era da Globalização a qual nos encontramos, o ensino traz novos desafios aos educadores. A Cartografia e suas tecnologias vêm sendo empregadas de forma crescente no ensino público paulista, e esta integração da cartografia e das geotecnologias à educação escolar contribui para que os alunos sejam capazes de melhor entender as relações entre meio-ambiente e sociedade (no caso da Geografia). 
"Práticas com mapas eram atividades subutilizadas nas escolas. Hoje se transformaram em preocupação fundamental para o ensino de geografia. Importantes noções, como a própria localização espacial, são tratadas com o auxílio de mapas". (ALMEIDA, Rosangela Doin de. Cartografia escolar, 2009)

Ao darmos atenção à situação geral atual do ensino brasileiro, vemos, a partir mesmo de provas de vestibulares, o conhecimento cartográfico como requisito para que os alunos consigam chegar ao correto resultado de questões interdisciplinares.

No caso paulista especificamente, observamos um investimento do Governo paulista para com a alfabetização cartográfica, sendo exploradas de forma disciplinar e interdisciplinar, ao passo que essa cobrança e utilização de documentos cartográficos e geotecnologias encontram-se não apenas nos conteúdos dos "Cadernos" da disciplina de Geografia, como também de História e outras.

Estudo diz que "78,07\% de todas as Situações de Aprendizado contidas em todos os volumes de todos os anos do Caderno do Professor de Geografia do ensino fundamental II e ensino médio, do ano de 2009 Estado de São Paulo, utilizam a Cartografia e/ou Sensoriamento Remoto como auxílio no ensino" (BASOTI, LEME, PANCHER, ZANILATTO. 2013). Podemos concluir que há uma forte cobrança na grade curricular do ensino básico brasileiro, voltada para a linguagem cartográfica e suas tecnologias.

Em sua maioria, as competências e habilidades a serem trabalhadas com os alunos nesses conteúdos são: interpretação de mapas e de imagens orbitais, análise de dados na forma de gráficos, tabelas e linguagens cartográficas.

O presente artigo é componente de um projeto financiado pela PROEX intitulado "Geotecnologias para alfabetização cartográfica de professores de Geografia do ensino da rede pública”. Este projeto procurou capacitar os educadores da disciplina Geografia do ensino básico no uso disciplinar e interdisciplinar da cartografia e suas tecnologias na sala de aula.

Segundo o INPE, o conhecimento dos educadores influi positivamente na qualidade do aprendizado, daí a elaboração das oficinas de geotecnologias para trabalharmos a capacitação dos educadores - ao concordarmos que os educadores são os elementos principais para a disseminação de geotecnologias junto à comunidade de ensino.

\section{PROCEDIMENTOS METODOLÓGICOS}

Foi realizada uma análise em todos os volumes de todos os anos do Caderno do Professor de Geografia do ensino fundamental II e ensino médio, do ano de 2009 - Estado de São Paulo, e seguinte levantamento 
estatístico para que tivéssemos ciência do como a Cartografia e o Sensoriamento Remoto vem sendo cobrados na grade curricular da disciplina Geografia, do ensino básico.

"A análise qualitativa dos temas foi sendo realizada em conjunto com a quantitativa. Ao verificarmos se havia ou não algo relacionado ao tema, já foi sendo feito um resumo de cada Situação de Aprendizado seguido de uma análise sobre se a cartografia e o sensoriamento remoto foram utilizados ou não em determinado tema da Geografia. Em caso positivo, verificamos como os temas foram utilizados durante as práticas de ensino e em que área da Geografia foram utilizados. Em caso negativo, foi observado se realmente não caberia o uso destes dois temas e se caberia, em que e como eles poderiam ser utilizados." (BASOTI, I., et al.; O uso das geotecnologias para o ensino da Geografia: uma análise do caderno do professor. Rio Claro. 2013.)

A partir daí, partimos para a elaboração das oficinas de capacitação para professores, de modo a contribuir para uma formação continuada com aulas teóricas e práticas e abrangendo conteúdos como interpretação de mapas e de imagens orbitais, GPS, Google earth, Google maps, Estatcart, Spring etc.

Inicialmente se fez necessário uma capacitação exclusivamente da ciência cartográfica a esses educadores (Figura 01), de modo que nem todos tinham domínio sobre esta ciência ou sobre elementos fundamentais da mesma, tais como escala, coordenadas geográficas e UTM, entre outros princípios básicos. Realizada a capacitação dos professores na área pura e específica da Cartografia, pudemos avançar para as oficinas de geotecnologias para a capacitação e atualização do conhecimento na área.

\section{Resultados}

Embora os "Cadernos do Governo do Estado de São Paulo" ilustrem e exemplifiquem diversos conteúdos curriculares utilizando imagens orbitais, há um déficit de aproveitamento deste recurso didático pelos educadores - devido até mesmo, à falta de informação sobre essa tecnologia, em constante processo de inovação.

Como já citado anteriormente, os educadores se encontraram carentes de uma capacitação da ciência cartográfica exclusivamente, de modo que nem todos tinham domínio sobre esta ciência ou sobre elementos fundamentais e princípios básicos da mesma. Realizada a capacitação dos professores na área pura e específica da Cartografia, pudemos avançar para as oficinas de geotecnologias para a capacitação e atualização do conhecimento na área.

As oficinas de geotecnologias à educação escolar contribuem para que os professores obtenham autonomia no assunto de integralização de geotecnologias à disciplina de Geografia do ensino básico, proporcionando aos alunos um melhor entendimento das relações entre meio-ambiente e sociedade. 


\section{Conclusão}

A cartografia e o sensoriamento remoto vêm sendo incluídos cada vez mais em nosso dia-a-dia e precisamos estar em constante atualização de conhecimentos e adequação nos materiais didáticos.

Segundo Gonçalves (2005), a introdução das novas tecnologias, no ensino, é irreversível no Brasil e no mundo. Desta forma, se faz necessária a atualização na formação dos docentes, junto a pesquisas afim de se verificar performance didático/pedagógica desses recursos, junto aos alunos e professores. Ainda segundo Gonçalves (2005), é necessário “adaptar as imagens orbitais para seu uso em sala de aula; e adequar os materiais didáticos".

O objetivo do projeto foi alcançado ao passo que este aproximou os docentes da Rede Pública de ensino às atualizações nas áreas de Cartografia e Geotecnologias. Isso porque não foram elaborados objetivos de forma utópica, mas partindo do básico, dos fundamentos das disciplinas e dando atenção necessária para que os professores pudessem recordar e aprender.

Ficam aqui os sinceros agradecimentos à Profa. Dra. Andréia Medinilha Pancher, professora orientadora deste Projeto de Extensão, que possibilitou a realização destas atividades e cuja participação foi de fundamental importância, aos alunos bolsistas envolvidos, aos professores da Rede Pública que se dispuseram a participar do curso de capacitação e à Pró-Reitoria de Extensão Universitária - PROEX que financiou tal atividade.

\section{Figuras e Tabelas}

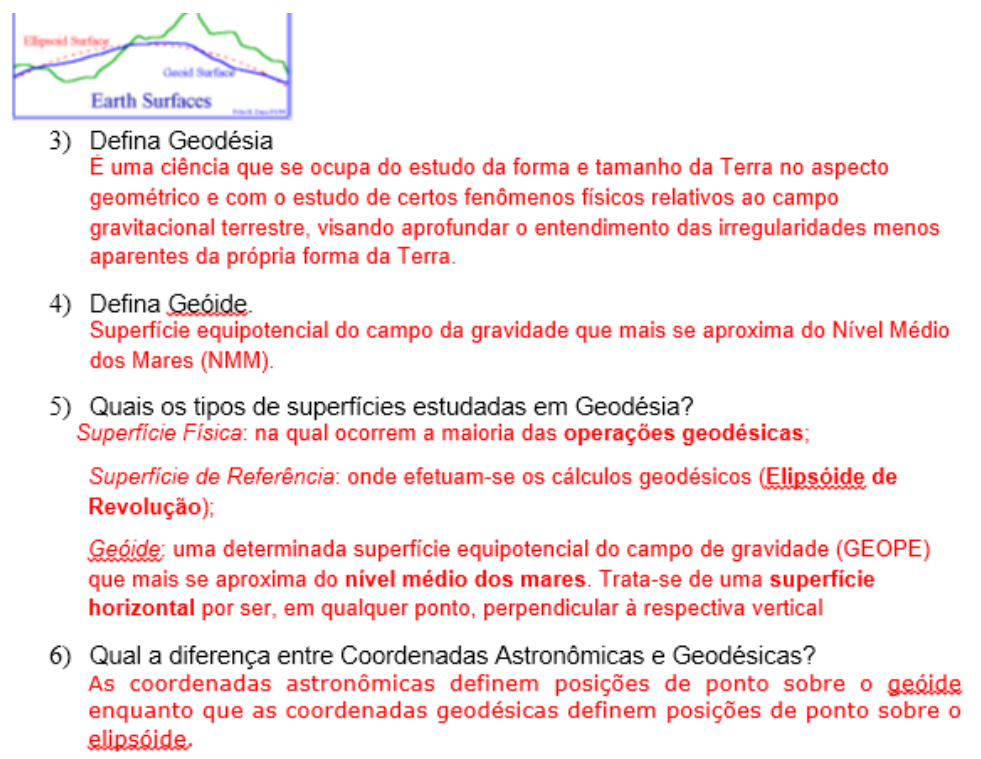

Figura 01: Capacitação em Cartografia (fundamentos) 


\section{REFERÊNCIAS}

ANDRADE, M. A; Caminhos e Descaminhos da Geografia, 2006.

BASOTI, I., LEME, A., PANCHER, M., ZANILATTO, R. O uso das geotecnologias para o ensino da Geografia: uma análise do caderno do professor. Rio Claro. 2013.

CORREA, M. G. G.; FERNANDES, R. R.; PAINI, L. D. Os avanços tecnológicos na educação: o uso das geotecnologias no ensino de geografia, os desafios e a realidade escolar. Maringa, v. 32, n. 1 p. 91-96, 2010.

DEETZ, C. H; Cartografia. 2006.

DUARTE, P. A; Fundamentos de Cartografia. 1994.

FITZ, P. R; Cartografia básica. 2008.

GONÇALVES, M.I; Uso do sensoriamento remoto na produção do conhecimento escolar como proposta para utilização das tecnologias espaciais na sala de aula. In. Anais XII Simpósio Brasileiro de Sensoriamento Remoto. Goiânia, 2005, p. 1289-1296.

JOLY, F. A cartografia. Campinas: Papirus, 2004.

SANTOS, S. R.; SANTOS, V. P. dos.; SOUZA, U. B. de.; BORGES, E. F.; SANTOS, P. S. Geotecnologias aplicadas ao ensino de Geografia: Um estudo de caso na cidade de Barreiras-BA. Anais XV Simpósio Brasileiro de Sensoriamento Remoto - SBSR, Curitiba, PR, Brasil, 30 de abril a 05 de maio de 2011, INPE p.3394-3399.

Santos, V. M. N; O uso escolar de dados de sensoriamento remoto como recurso didático pedagógico no estudo do meio ambiente. São José dos Campos, INPE, 2002.

SILVA, F. G. da.; CARNEIRO, C. D. R. As geotecnologias nos livros didáticos: uma análise para o ensino médio. Anais XV Simpósio Brasileiro de Sensoriamento Remoto - SBSR, Curitiba, PR, Brasil, 30 de abril a 05 de maio de 2011, INPE p.3295-3301. 


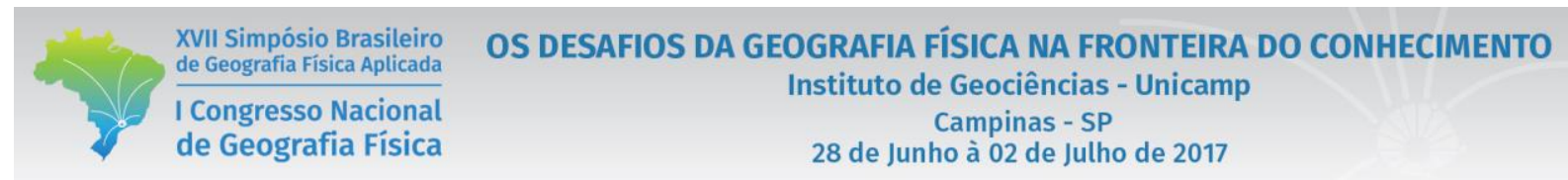

Silva, A. S; Sistemas de informações geo-referenciadas. 1999. 